\title{
Factor VII Inactivation
}

National Cancer Institute

\section{Source}

National Cancer Institute. Factor VII Inactivation. NCI Thesaurus. Code C131665.

Presence of inactivating antibodies to factor VII in the blood. 